\title{
Following a TRAIL: Update on a ligand and its five receptors
}

\author{
Fiona C. KIMBERLEY ${ }^{1}$, Gavin R. SCREATON ${ }^{2, *}$ \\ ${ }^{1}$ Weatherall Institute of Molecular Medicine, Human Immunology Unit, John Radcliffe Hospital, Oxford OX3 9DS, UK \\ ${ }^{2}$ Department of Medicine, Hammersmith Hospital, Imperial College, Du Cane Road, London W12 ONN UK.
}

\begin{abstract}
Identification of tumour necrosis factor apoptosis inducing ligand (TRAIL), a TNF family ligand, sparked a torrent of research, following an initial observation that it could kill tumour cells, but spare normal cells. Almost a decade after its discovery, and with five known receptors, the true physiological role of TRAIL is still debated and its anti-tumorigenic properties limited by potential toxicity. This review takes a comprehensive look at the story of this enigmatic ligand, addressing its remaining potential as a therapeutic and providing an overview of the TRAIL receptors themselves.
\end{abstract}

Keywords: TRAIL, apoptosis, cancer.

\section{TRAIL}

Tumour necrosis factor apoptosis inducing ligand (TRAIL, Apo2L) is a type II membrane bound TNF family ligand that is highly homologous to cytotoxic FasL, displays widespread expression and is up-regulated on lymphocyte activation $[1,2]$. Crystal structures have shown that, like other TNF ligands, it occurs as a trimer (Fig. 1). It can be cleaved from the membrane by cysteine proteases to generate a soluble form of the ligand [3], and specifically from activated monocytes and neutrophils [4]. Its main function is to induce apoptosis and activate the transcription factor $\mathrm{NF}-\kappa \mathrm{B}$.

Interest in TRAIL mounted, following the observation that TRAIL could selectively kill cancer cells but not normal cells, and consequently, several receptors for TRAIL quickly emerged (Fig. 2). Initially, death receptor 4 (DR4/TRAILR-1) was the only known TRAIL receptor, but its widespread expression on both malignant and normal cells, at similar levels, did not explain the observed TRAIL selectivity [5]. A second receptor, death receptor 5 (DR5/TRICK-2/KILLER/TRAILR-2), was then identified using the sequence of the intracellular death domain of DR4 in an expressed sequence tag (EST) database search [6-8]. However, DR5 was also widely expressed on both normal and malignant cells. Another EST database search was carried out, this time using the extracellular sequence of the death receptors, the putative TRAIL binding region, and two new receptors were

\footnotetext{
${ }^{*}$ Correspondence: Gavin R. SCREATON
}

E-mail: g.screaton@imperial.ac.uk identified: decoy receptor 1 (DcR1/LIT/ TRID/ TRAILR3 ) and decoy receptor 2 (DcR2/TRUNDD/ TRAILR-4) [7, 9-13]. DcR1 had no death domain and was anchored to the membrane via a glycophosphatidyl inositol (GPI) tail, whereas DcR2 was found to have a truncated and non-functional death domain. Finally, a fifth receptor for TRAIL, osteoprotegerin (OPG), exists in a dimeric, soluble, secreted form [14]. Expression of the so-called decoys (DcR1 and DcR2) was initially found to be restricted to normal cells, and researchers thought they had found the answer for TRAIL's selectivity $[11,15]$. Thus, it was proposed that the decoys on normal cells could sequester TRAIL and divert it away from the death receptors, whereas absence of the decoys on cancerous cells left them susceptible to TRAIL-induced death.

\section{A role for TRAIL in cancer therapy}

Simple transfection experiments showed that addition of the decoys conferred protection from TRAIL-mediated killing $[9,10,16]$. It appeared that cancer cells had left themselves 'unguarded' through the loss of decoy expression. Hopes for TRAIL as the new 'golden bullet' for cancer cells grew, and several in vivo studies have shown promising use of recombinant TRAIL with marked tumour regression $[17,18]$. In multiple myelomas it overcomes the drug resistance that so far has prevented an effective cure for this cancer [19]. Studies also suggest that an increased potency against tumours is achieved when TRAIL is administered as a combination therapy with preexisting anti-cancer drugs. An increase in TRAIL-induced apoptosis was seen with etoposide, AraC and doxorubicin; 
A

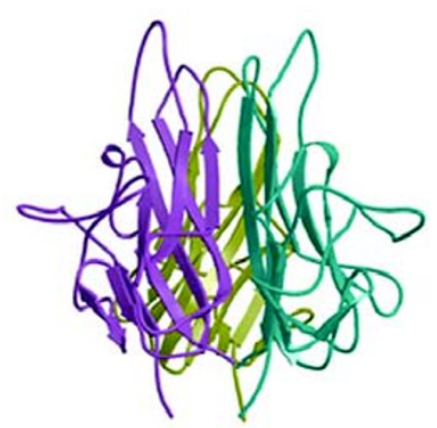

B

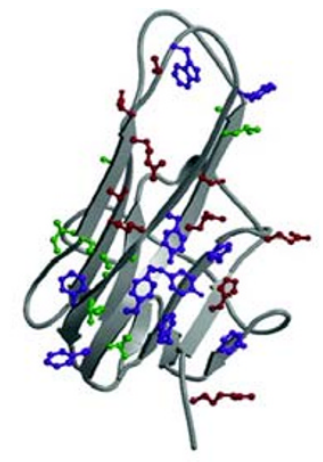

Fig. 1 Crystal structure of TRAIL. (A) Ribbon structure of the TRAIL trimer (side view). (B) Ribbon structure of TRAIL monomer illustrating the residues involved in trimerisation: aromatic rings in purple, hydrophobic residues in green and polar residues in red.

the phenomenon attributed to an increase in DR5 levels, which can be up-regulated in response to DNA damage $[20,21]$; the same effect was observed in glioma cells [22]. Similarly, chemotherapy augments TRAIL-induced apoptosis in breast cancer and allowed TRAIL-sensitisation of the AIDS sarcoma [23, 24], and human hepatocellular carcinoma cells were markedly sensitized to TRAIL with 5'Fluorouracil (5'FU) [25]. In addition, enhancement of TRAIL sensitivity has been reported when used with irradiation [26].

However, the true potential for TRAIL as a therapeutic is marred by a controversial and as yet unresolved debate over its potential toxicity to human hepatocytes. In vitro studies showed that normal human hepatocytes were sensitive to TRAIL [27]. Another study proposes a critical role for TRAIL in hepatic cell death and inflammation [28]. In a mouse disease model of hepatitis, a marked increase in TRAIL expression, though not the receptors, was observed, and injection of soluble DR5 provided some relief. It has been argued that the soluble and membranebound forms of TRAIL may have differing activities, as well as different functions across species, but liver damage in mice also arose in response to membrane-bound TRAIL $[3,29]$. TRAIL apoptosis of human stellate cells, thymocytes, prostate epithelial cells and neural cells has also been observed under certain conditions, raising the concern that these too may be damaged by a TRAIL therapeutic [30-34]. Whilst experiments had shown effective killing of transformed cells with FasL, the massive systemic toxicity and the lethal effect of FasL and anti-Fas antibody, called an early halt to any therapeutic advances [35]. Likewise, despite the observed anti-cancer properties

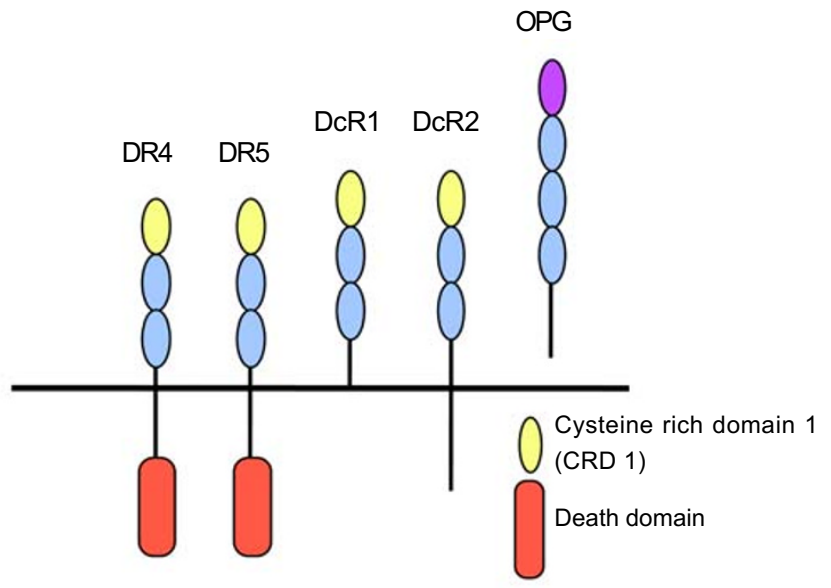

Fig. 2 Schematic of the five TRAIL Receptors. The extracellular cysteine-rich domains are represented by coloured ovals; yellow, for the first partial CRD1, which has one cystiene bond, and the other full cysteine rich domains in blue.

of TNF $\alpha$, problems with TNF-toxicity at high doses and even pro-angiogenic properties have also limited its use in cancer treatment 5 (reviewed in [36]). So, the possible toxicity of TRAIL is an added disappointment. Hopes were raised with a simple human DR5 monoclonal antibody, that can mimic TRAIL by causing receptor clustering, and was shown to lack toxicity against human hepatocytes in vitro, while TRAIL itself remained toxic [29]. The antibody remained effective at killing tumour cells in vivo, but such antibody killing requires crosslinking with dynabeads to be effective, which can happen through $\mathrm{Fc}$ receptors in vivo. Thus, a human antibody against the death receptors that can induce apoptosis in tumours but not the liver, has yet to be found.

Among the drive for therapeutics, studies of numerous normal and tumour cell lines have failed to show a definite correlation between expression of the TRAIL receptors, at both the mRNA and protein level, and protection from, or susceptibility to, apoptosis [37-39]. Current literature describes a myriad of ways in which sensitivity to TRAIL may be controlled which is often cell-type dependent. In one case the high levels of death receptors on the surface but a lack of sensitivity were explained by the presence of a polymorphism in the death domain of DR4, leading to dominant negative inhibition of signalling [21]. However, the presence of internal regulators of apoptotic machinery such as cellular FLICE like inhibitory protein, cFLIP (FLAME, CASH, CLARP and MIT-1), an inhibitor of caspase activation, was another important determinant [21, 40]. More recently, the synergistic effect of 5'FU along with TRAIL in killing cancer cells was attributed to the down-regulation of cFLIP [25]. Loss of cFLIP using RNA 
interference demonstrated a crucial role for this internal regulator. The status of $\mathrm{p} 53$, a tumour suppressor gene that responds to DNA-damage and can up-regulate DR5, was also influential in some cell lines [41, 42].

The presence or absence of the decoys was soon found to be an unreliable indicator of sensitivity, and the original hypothesis assuming a simple difference between the expression of the death receptors and the decoys, was in doubt. Indeed, in some tumours, up-regulation of the decoys and TRAIL expression has been implicated as an immune evasion mechanism [43]. It is now apparent that different tumour cell lines respond to TRAIL in different ways, and highlights the importance of treating each type of cancer individually. The future of TRAIL as a cancer therapy, for the time being, may be limited to a role in local treatment of tumours in conjunction with current DNA-damaging therapies, although effective targeting of internal regulators in conjunction with TRAIL might also be hopeful.

\section{Functions of TRAIL}

While the activity of TRAIL as an anti-tumour agent has been heavily pursued, the true function of TRAIL under normal physiological conditions remains unanswered. TRAIL became a prime candidate for the negative selection of immature thymocytes, following lack of evidence for the involvement of Fas/FasL, this too an area of much controversy. Studies using lpr mice (with Fas mutations) have suggested that Fas may modulate negative selection, and they also show a crucial role for Fas in T-cell development [44]. However, other studies have shown that Fas deficient mice develop a normal T-cell repertoire [45]. It is now accepted that the major role of Fas is in the deletion of peripheral T-cells and in activation induced cell death (AICD) (reviewed in [46]).

In our laboratory, a study using cultured thymocytes and anti-CD3 treatment as a model for negative selection, showed an activation-induced increase in TRAIL sensitivity of thymocytes, but not peripheral T-cells [32]. However, death of activated thymocytes was found to be TRAIL-independent since it could not be blocked using soluble DR5-Fc. Thus, TRAIL did not appear to be a major mediator of negative selection. This result was confirmed in TRAIL-deficient mice, which showed no abnormalities in lymphoid or myeloid homeostasis or function [47]. Interestingly, a second study of TRAIL knockout mice presents a more crucial role for TRAIL [31]. They describe an enlarged thymus and attribute this to a defect in thymocyte apoptosis, claiming an essential role for TRAIL in thymic deletion. The TRAIL ${ }^{-/}$mice showed increased numbers of immature thymocytes and a failure to induce apoptosis of activated T-cells both in vitro and in vivo. They also proposed an important role for TRAIL in mediating auto-immunity, showing that the TRAIL deficient mice have an increased susceptibility to collagen-induced arthritis and streptozotocin-induced diabetes. The TRAIL ${ }^{-/-}$mice were more prone to disease development and showed accelerated disease progression. However, the mice do not develop spontaneous autoimmune disease in the first few months.

If TRAIL is a key player in negative selection, it is clear that it cannot work alone or through its conventional route. Mice lacking FADD or with caspase- 8 blocked via transgenic CrmA (a viral inhibitor of caspase-8), two key components in the TRAIL signalling pathway, showed no thymic abnormalities [48, 49]. Rather, mice deficient for FADD showed proliferative defects in their T-cell populations that were independent of caspase-8. Interestingly, mice deficient for Bim, a Bcl-2 family pro-apoptotic component, have severe defects in thymic deletion [50]. An elegant hypothesis was proposed to account for much of the evidence so far [51]: following TCR-stimulation, TRAIL receptors are up-regulated; their subsequent engagement induces activation of JNK which in turn inactivates Bcl-2. The now inactive Bcl-2 then releases Bim, which can trigger death via the mitochondrial pathway. Finally, a third study of TRAIL ${ }^{-/}$mice refute the findings by Lamhamedi-Cherradi et al [52]. Using four different models for negative selection they argue that TRAIL has no role in early thymic deletion.

With a failure to identify a true role for TRAIL, many now believe that the initial observation of anti-tumourigenicity is in fact its true function, and that TRAIL fulfils an immune surveillance mechanism within the body in the innate immune response, against both tumours and virusinfected cells. It has been shown to be up-regulated on NK-cells in response to IFN $\gamma$, particularly liver NK cells, and serves an anti-metastatic function $[53,54]$. Similarly, IFN $\gamma$-stimulated monocytes, peripheral blood T-cells, dendritic cells and $\mathrm{CD} 4^{+} \mathrm{T}$-cells demonstrate TRAILdependent anti-tumourigenicity [55-57]. IFN $\gamma$-dependent events also govern cytomegalovirus (CMV) up-regulation of TRAIL and its activity against virus-infected cells [58]. HIV-infection reportedly sensitises previously resistant $\mathrm{T}$ cells to TRAIL-mediated death [59], an observation supported by other work $[60,61]$. Similarly, TRAIL resistant colonic epithelial cells are rendered sensitive upon infection with human CMV [62]. This immune surveillance role for TRAIL is also supported by observations in $\mathrm{TRAIL}^{-/-}$ mice [47]. While the mice show no spontaneous tumour development, upon challenge with a TRAIL sensitive cancer cell line they develop tumours more rapidly than the wild type mice, and these tumours occur almost exclusively in the liver.

The many cancer studies have revealed a definite role for TRAIL in the liver, and it has been postulated that this 
waste ground for dying lymphocytes is cleared through the actions of TRAIL [53]. This surveillance role is also thought to mediate protection of cells at sites of immune privilege, such as along the syncitiotrophoblast of the placenta [63] and in the eye [64]. Some research suggests a role in the deletion of B-cells [65], and another study describes TRAIL as a negative regulator of erythropoesis [66], although no anaemia was observed in TRAIL $^{-/-}$mice [47]. New evidence that TRAIL can exhibit potent proangiogenic properties, along with the anti-tumourigenicity heavily discussed, suggests a Jekyll and Hyde persona for TRAIL [67].

Adverse affects of TRAIL include the discussed role in hepatic disease [27], induction of apoptosis and inflammatory gene expression in endothelial cells [68], and its role in reovirus-induced apoptosis, which is IFN $\gamma$-mediated and a major contributor to the viral pathology [69]. While all these data are important in discerning the true role of TRAIL, mouse models are somewhat limited since mice only express one death receptor, most closely related to human DR5 [70]. Two mouse homologues of human DcR 1 and 2 also exist, termed mDcTrailr1, and msDcTrailr2. MsDcTrailr1 has a GPI-anchor, whereas msDcTrailr2 has two splice variants, the longer form with a transmembrane domain and a short cytoplasmic region and a short soluble secreted form expressing only the ECD [71]. These have the highest degree of homology to their human counterparts in the ligand binding region, but have three disulphide bonds in the first CRD, compared with only one in DcR1 and 2. These distinct differences in structure suggest independent evolutionary origins from the human receptors, further limiting the mouse model in studies of the TRAIL/TRAIL receptor axis. In addition, these murine models do not address long-term effects such as ageing, and true disease challenge.

\section{TRAIL receptor triggering}

The crystal structure of a complex between TRAIL and DR5, solved in our laboratory and others, revealed the trimeric ligand interdigitated with three monomeric receptors [72-74]. The receptors are positioned neatly at the interfaces between the ligand monomers with the contact surface in the second and third CRD (Fig. 3). Such crystal complexes of other members of this family led to the 'ligand induced trimerisation model', in which the incoming trimeric ligand recruits three receptor molecules (Fig. 4). This induced juxtaposition of the intracellular receptor domains is then sensed inside the cell and facilitates the recruitment of downstream signalling components, triggering the internal signalling cascade. The ligand-induced trimerisation model was consequently widely accepted and became the paradigm for receptor triggering in the TNFR superfamily. However, studies of both Fas and TNFR1 defined a ligand-independent oligomerisation domain in the extracellular region, termed the pre-ligand assembly domain (PLAD) $[75,76]$.

These observations invoked consideration of an alternative model for receptor triggering, in which the receptors could pre-associate prior to ligand binding. The PLAD was shown to be necessary for subsequent ligand binding, and was proposed as the mechanism by which the sometimes promiscuous TNF family ligands are as-

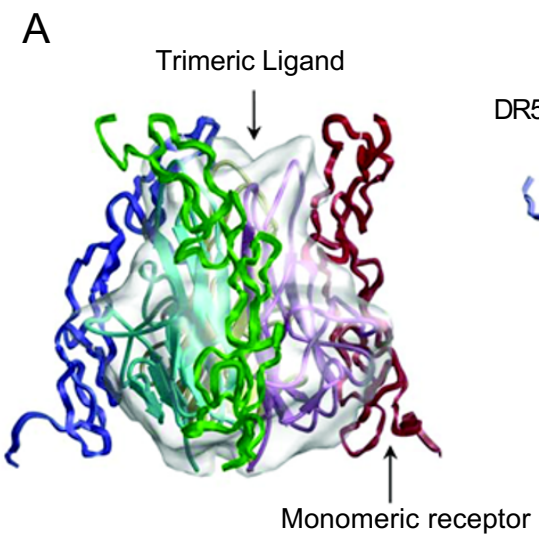

B

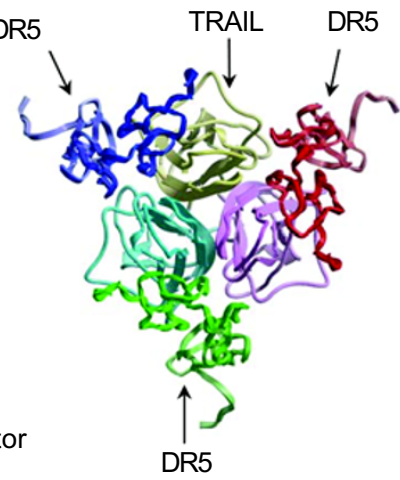

Fig. 3 Crystal complex of TRAIL/DR5. (A) View of the death receptor-5/TRAIL complex: TRAIL monomeric units are yellow, pink and turquoise encased in a clear shell, and the interdigitated DR5 monomers are coloured red, green and blue; this is a side view. (B) The complex as depicted in $\mathbf{A}$, but viewed down a threefold axis, providing a top view of the complex. Pictures are taken from Mongkolsapaya et al. Nat Struct Biol. 1999 Nov;6 (11):1048-53 


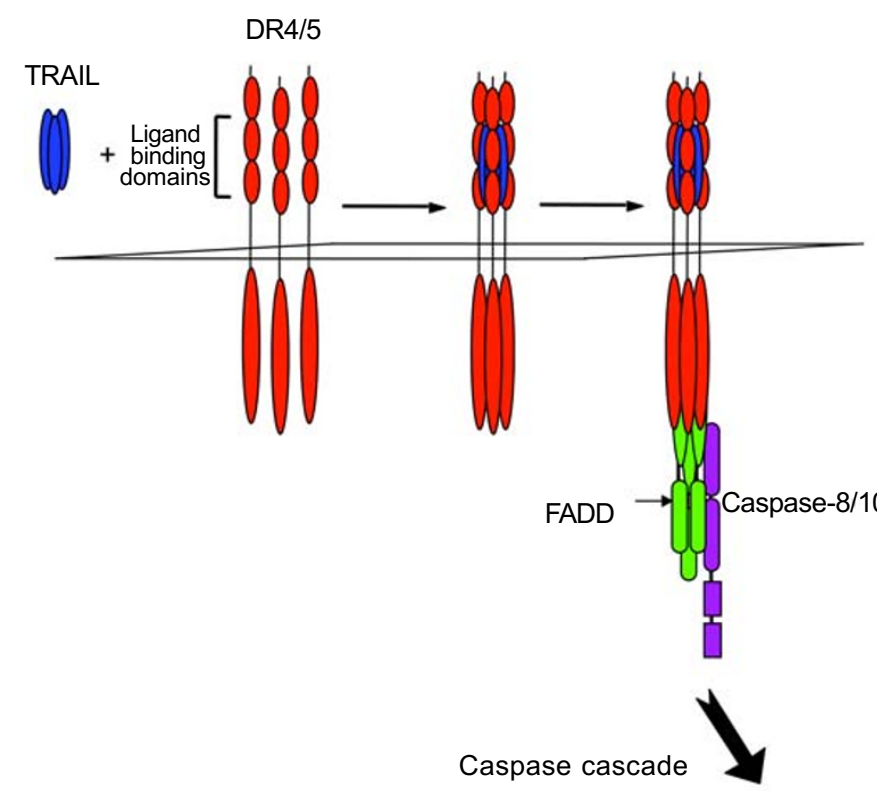

DEATH

Fig. 4 The Ligand induced trimerisation model. The incoming trimeric ligand recruits three receptors into a complex. This induced juxtaposition of the intracellular domains triggers recruitment of the intracellular signalling components leading to either the caspase cascade and cell death, or activation of NF- $\mathrm{KB}$. sured a homotypic trio of receptor molecules in any given complex (Fig. 5). If such multimeric assemblies do exist, it would suggest that signalling involves a large scale recruitment of receptor at the cell surface leading to a mosaic model of multi-clustering (Fig. 6). Whether a distinct PLAD exists for the TRAIL receptors has not been shown. However, unlike Fas and TNFR1, they have only a partial CRD1 (putative PLAD) with one cysteine bond compared to the usual complement of three.

\section{On the receiving end}

Disappointments with TRAIL as a therapeutic have led researchers back to targeting death via the TRAIL receptors themselves. The TRAIL receptors belong to the tumour necrosis factor receptor (TNFR) superfamily, also known as the nerve growth factor receptor superfamily (NGFR), and are related by virtue of their structure. They are type I transmembrane proteins with a common structural framework defined by the presence of cysteine residues in highly conserved locations within the extra-cellular domains, termed cysteine-rich domains (CRD) (reviewed in [77]).

\section{Death receptor 5}

Death receptor 5 is a non-glycosylated protein with $58 \%$ overall homology to DR4, the greatest homology in the intracellular death domain. It has one partial CRD (with only one cysteine bond, compared to the full complement of three) and two full CRDs in the extracel-
A

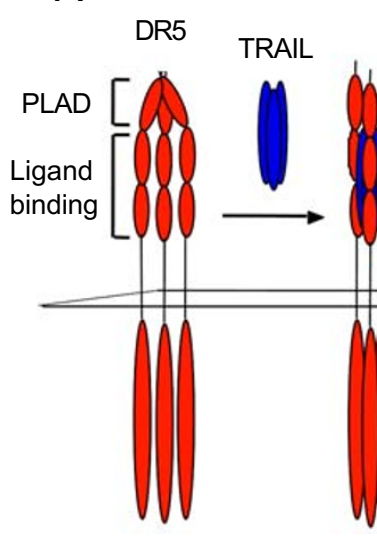

B

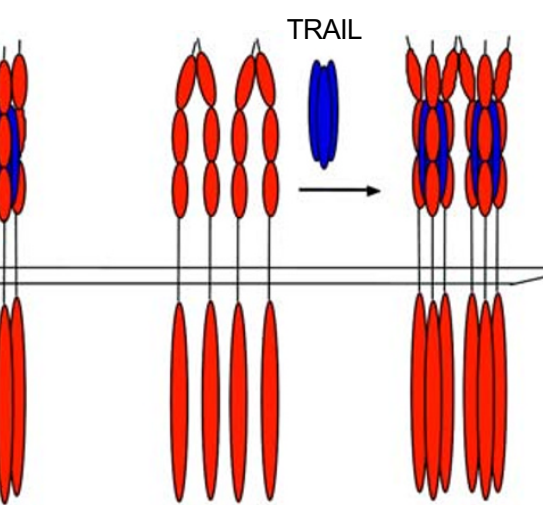

Fig. 5 Proposed models for the PLAD. (A) Conformational change: Receptors are pulled into trimers by virtue of the PLAD and conformational change upon ligation juxtaposes intracellular components of the receptor. (B) Induced super-clustering: Receptors are dimerised by the PLAD (as in the TNFR1 dimeric crystal) and ligation results in molecular super-clustering, as a consequence of co-operative recruitment. 
A

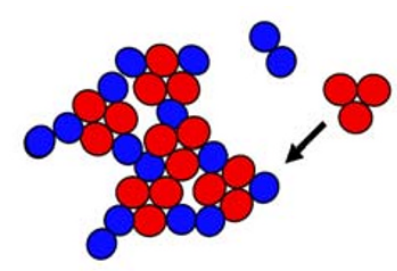

B

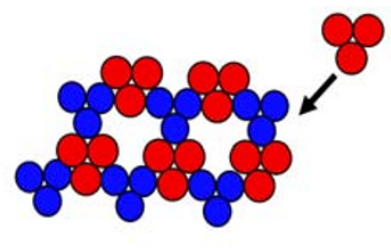

Fig. 6 Mosaic models for ligand recruitment. As in the induced super-clustering model, pre-associated receptors can rapidly and co-operatively recruit ligand, causing a mosaic pattern on the cell surface. These diagrams represent a top view of receptor and ligand. (A) Pre-associated back-to-back receptor dimers (blue) recruit trimeric ligand (red). (B) Possible trimeric receptors (blue) recruit trimeric ligand (red).

lular domain. It is expressed in a wide range of tissues but is strongly up-regulated on activated lymphocytes. Interestingly, there are two forms of DR5 which result from alternative splicing: DR5A/TRICK2A (short) and DR5B/TRICK2B (long). They differ in the presence of a 23 amino acid extension between the transmembrane domain and the start of the CRDs [8]. These two isoforms do not appear to have distinct functions and it has been suggested that the longer form may have arisen due to retention of an intron, since the sequence at either end matches that of a consensus splice site. DR4 does not contain this additional sequence and is therefore more closely related to DR5A. Over-expression of DR5 through transient transfection causes spontaneous cell death, due to clustering of the death domains [8].

The main function of DR5 is in its role as a death receptor on many different cell-types. A specific physiological role for either DR4 or DR5 has yet to be defined, although the existence of two death receptors for the same ligand might suggest an essential role in tissue homeostasis. Reports in the literature have been driven by the TRAIL sensitivity of cancer cell lines. Specifically, up-regulation of DR5 has been reported in response to treatment with DNA-damaging cancer therapeutics [20]. In addition, loss of function of DR5 in head, neck and gastric carcinomas may demonstrate a role for the apoptotic activity of DR5 in mediating uncontrolled proliferation [78, 79]. Hence, DR5 is gaining a reputation in the role of a tumour regulator.

A link between DR5 and the status of the p53 tumour suppressor gene has also been extensively studied. $\mathrm{Mu}-$ tations in the p53 gene are some of the most predominant occurring in over $50 \%$ of cancers. This transcription factor controls a crucial checkpoint in the cell cycle and can mediate apoptosis of damaged cells by two mechanisms: via the mitochondrial pathway through generation of reactive oxygen species (ROS), and via a receptor-mediated pathway involving DR5 (reviewed in $[41,80]$ ). Studies have shown that DR5 is up-regulated in response to $\gamma$ irradiation, in particular in the spleen and small intestine, and that this is a p53-mediated event [81]. The presence of p53-response elements within the DR5 promoter has also been shown [82].

Specifically, a role for DR5 in mediating apoptosis of synovial fibroblasts has been described [83]. In rheumatoid arthritis pathology is driven by proliferating synovial fibroblasts that exhibit properties similar to transformed cells, and secrete metalloproteinases (MMPs) that exacerbate inflammation within the joint. These cells up-regulate DR5 expression and seemingly escape TRAIL-mediated apoptosis. Whether this is the cell's own attempt to stunt proliferation is unknown. However, they were effectively targeted and killed with a monoclonal antibody against DR5. This same monoclonal antibody (TRA-8) has been shown to kill cancer cells effectively without hepatic toxicity, showing diverse potential as a future therapeutic [29, 84].

\section{Death receptor 4}

Death receptor 4 was the first of the TRAIL receptors to be identified [5]. Functionally, its story is similar to that of DR5, and may play an identical immune surveillance role, since its major function is the induction of apoptosis. A clear distinction between the roles of DR4 and 5 has yet to be defined, but it is likely that there is some functional redundancy between the two. Several mutations within DR4 have been reported in cancer cells [85-87]. Specifically, a polymorphism in the ligand binding domain of DR4 has been linked to a higher incidence of bladder cancer [88], and the expression of DR4 in colon cancers was linked to a favourable prognosis [89]. Like other cancers, the presence of DR4 renders them susceptible to killing via TRAIL [90]. DR4, like DR5, is also p53-inducibe, and treatment of tumours has been shown to be more effective in the presence of DNA-damaging therapeutics [91, 92]. It can be down-regulated by adenovirus proteins [93], but conversely, up-regulated by hepatitis B [94].

\section{The decoy receptors}

Cloning of the decoy receptors rapidly followed that of the death receptors. DcR1 is GPI-tethered to the membrane, and is much less widely expressed than the other TRAIL receptors; transcripts were found predominantly on peripheral blood lymphocytes (PBLs) [10, 13]. It appears to have minimal signalling capacity, and unlike the death receptors, over-expression does not cause apoptosis, but instead blocks it. Its ability to inhibit apoptosis has been shown through transient transfection and through inhibition of TRAIL-induced apoptosis by DcR1-Fc [10]. The possibility that it can elicit direct signalling via its GPI 
anchor has not been studied, but with increasing research describing the potency of GPI signalling, this certainly invites investigation [95]. DcR1 has five glycosylation sites, and research from our laboratory suggests that deglycosylation can increase its affinity for TRAIL, providing a possible regulatory mechanism (unpublished data). The existence of soluble DcR1 has also been shown, although experiments with PI-PLC, an enzyme that cleaves many GPI-linked proteins, showed minimal cleavage of $30 \%$, compared to $80 \%$ with a control protein [10].

DcR2 has a high degree of homology to the other TRAIL receptors, approximately $58-70 \%$, and is widely expressed [9]. It has three potential N-glycosylation sites and a truncated intracellular domain, lacking 52 of the 76 amino acids that encode the predicted death domain, but overexpression does not induce death [6]. A physiological role for either of the decoy receptors has not been shown; instead reports have been concerned with their presence or absence on tumours, and their ability to inhibit cell death. There is evidence to suggest that the decoy receptors are also up-regulated in response to p53-sensed DNA damage [16]. This does not fit well with an immune surveillance role for the death receptors in the elimination of DNAdamaged cells, where up-regulation of the decoys would surely counteract this event. However, the four TRAIL receptors are located in the same chromosomal region (chromosome 8p21-22), so it is possible that in this system of p53 over-expression, otherwise weak signals for the decoys were amplified through the DR4 and 5 promoters.

\section{The real decoy?}

Discovery of the truncated TRAIL receptors posed several questions. What was their true physiologic role? Were they really present as dummy receptors to evade death receptor killing and if so, how was their expression regulated with respect to the functional death receptors? There are currently four major hypotheses regarding their action (Fig. 7). The first is the classic decoy hypothesis, whereby they are concomitantly expressed with the death receptors and compete for binding to TRAIL (Fig. 7A). If this competition theory is to hold, then one might expect the decoys to have a higher affinity for TRAIL in order to efficiently sequester TRAIL from the death receptors. Several studies have measured ligand binding of the TRAIL receptors $[9,10,14,96]$. The meaning of these numbers is complicated by the use of Fc-fusions (bivalent) binding a trimeric TRAIL, so provide only a measure of avidity rather than true affinity. One study concluded that TRAIL binds equally well to DR4, DR5 and DcR1 [10], yet a second describes a temperature-dependent rank order of 'affinities' (at $\left.37^{\circ} \mathrm{C}\right)$, with DR5 the greatest $(\mathrm{Kd}<2 \mathrm{~nm})$, followed by DR4, DcR1 and OPG, respectively; at $4^{\circ} \mathrm{C}$ and $25^{\circ} \mathrm{C}$ the binding measurements were comparable [96].
So, these studies provide little clues towards the true mechanism, but this hypothesis remains the most favoured, since transfection experiments show that the decoys can afford protection from TRAIL-mediated killing [9, 10]. The specific up-regulation of DcR1 was found in tumours of the gastrointestinal tract, possibly as a means of immune evasion [97]. However, such decoy activity within a physiological setting has yet to be proven, and many studies have found conflict between the sensitivity of a particular cell line and the expression pattern of the TRAIL receptors, suggesting an increased complexity to this mechanism [39]. Up-regulation of DcR 1 in response to TNF $\alpha$-stimulated NF- $\kappa$ B has been shown [98]. DcR1 was then able to confer protection from TRAIL-mediated killing, even though the levels of the other receptors were unaffected.

The second hypothesis is that the decoys are able to form mixed receptor complexes with the two death receptors, leading to an ineffective death inducing signalling complex, DISC (Fig. 7B). There is no current explanation for the mechanism by which TRAIL affords a homotypic trio of receptors in any given complex, and co-immunoprecipitation experiments show some evidence for heteromeric clusters of DR4 and 5, although these were less abundant [99]. In the case of DcR1, the presence of a GPI tail is likely to locate it in a distinct membrane domain to the death receptors, rendering such interactions unlikely, though this hypothesis cannot be eliminated for DcR2. Thirdly, there is some evidence to suggest that whilst DcR2 cannot activate death, it can activate $\mathrm{NF}-\kappa \mathrm{B}[9,100]$, although others have been unable to show this [16]. It is proposed that the subsequent up-regulation of anti-apoptotic genes by DcR2 might antagonise the death signal (Fig. 7C). Alternatively, even if DcR2 does not signal for either death or NF- $\kappa$ B, its intracellular domain may be able to deplete supplies of intracellular adaptors to prevent them binding to either DR4 or 5. However, this seems unlikely as this would mean the inhibition of other death receptors such as Fas and TNFR1. However, deletion studies of DcR2 demonstrated that the first 43 amino acids of the intracellular domain (ICD) were required for inhibition of TRAIL, and that DcR2 lacking its entire ICD does not protect from TRAIL-mediated death [16]. This therefore suggests that some intracellular mechanism plays an important role in any potential 'decoy' function.

Finally, the existence of a pre-ligand assembly domain (PLAD) in both Fas and TNFR1 raises the question as to whether such a domain exists in the TRAIL receptors $[75$, 76]. The four membrane-bound TRAIL receptors have comparable CRD architecture, and with such a high degree of homology in the extracellular domains, could cross-PLAD interactions be the answer to decoy activity? 


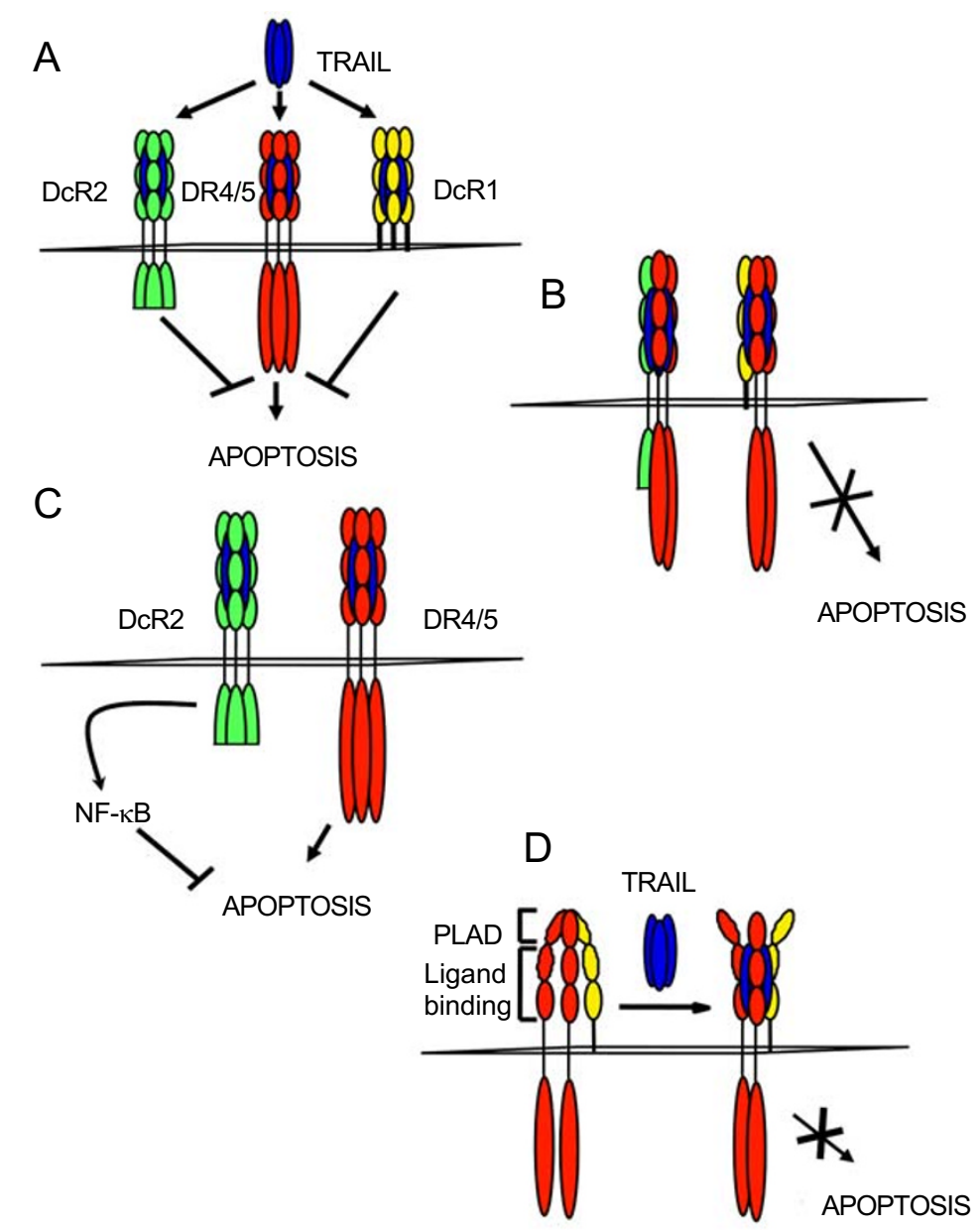

Fig. 7 Models for decoy activity. (A) Traditional competition theory, in which the decoys compete with the death receptors for the ligand. (B) Formation of mixed receptor complexes of both decoys and death receptors that can block the apoptotic

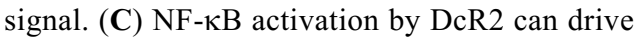
anti-apoptotic signals; NF- $\mathrm{BB}$ signalling through the death receptors might up-regulate DcR1. (D) Formation of mixed complexes by virtue of a PLAD will block subsequent TRAIL signaling.

If a pre-assembled trio of death receptors were to include one of the decoys, signalling upon ligand binding would be stunted (Fig. 7D). Might lateral receptor interactions define a novel flow of information between these molecules? This mechanism for inhibition presents a situation in which competition for the ligand plays no direct role, and could explain decoy activity despite differing affinities for TRAIL. Again, the location of DcR1 within lipid rafts would make this hypothesis less likely for DcR1, but it must be considered that DcR 1 and 2 might employ different means of decoy activity. Interestingly, one report showed that transient co-transfection of DcR2 with DR5 can protect the cell from the apoptosis that can occur as a result of the death domain clustering of DR5 [16].

\section{Osteoprotegerin}

Osteoprotegerin (OPG) is the only soluble TRAIL ligand, it is heavily glycosylated and occurs primarily as a disulphide linked dimer, although a small proportion can be found in a monomeric form [14, 101]. Unlike the other TRAIL receptors, it has four CRDs, each with only two disulphide bonds, except CRD2 which has three. It acts as a regulator of the development and activation of osteoclasts in bone remodelling. Normally, OPG ligand (also called TRANCE or RANKL) binds to RANK (receptor activator of $\mathrm{NF}-\kappa \mathrm{B}$ ), and stimulates osteoclastogenesis. OPG plays an important role as a decoy competing with RANK for OPGL binding, and the balance of these two receptors forms a regulatory mechanism [101]. OPG also has a role in the regulation of the immune response (reviewed in [102]). Studies with OPG deficient mice revealed B-cell defects, indicating an important role in B-cell development and maturation [103]. The role of OPG as a receptor for TRAIL is less clear. It has been proposed to serve as a survival factor, forming a second decoy activity by binding to TRAIL, and thus blocking apoptosis [14, 104]. Additionally, recent work demonstrates a potent blocking of RANKL plus macrophage colony stimulating factor (M-CSF) bone resorption, by TRAIL, indicating yet another potential complication for its therapeutic use [105]. This effect was attributed to specific inhibition of the RANKL-induced p38/MAPK pathway. However, TRAIL ${ }^{-/-}$mice showed no alteration in gross bone density or differentiation of osteoclasts, shed- 
ding doubt on a prominent physiological role for TRAIL as an OPG regulator, and vice-versa [47].

\section{TRAIL receptor signalling}

The TRAIL receptors DR4 and 5 have two overlapping modes of signalling: the cell death pathway, and a cell survival pathway involving activation of transcription factors. These pathways are distinguished by the formation of distinct complexes involving different internal adaptors (Fig. 8). The conventional apoptosis pathway is triggered through formation of the DISC $[106,107]$. This begins with the recruitment of a dual adaptor molecule, Fas associated death domain (FADD or Mort1). FADD contains its own death domain (at the Cterminus), and since these have a propensity to selfassociate it binds to the trimerised DDs of the Fas receptor complex $[108,109]$. At the N-terminus is the death effector domain (DED) which recruits procaspase-8, via its own DED. This oligomerisation drives self-cleavage to generate its active form which then activates other downstream effector caspases, notably caspase-3. The recruitment of FADD in the Fas pathway is well characterised, but the involvement of this adaptor in DR4 and 5 mediated apoptosis has been one of intense debate and conflicting results.

Early work did not find a role for FADD in DR4 and DR5 signalling [5, 7, 11, 110], yet others were convinced of FADD involvement [111-113]. Finally, FADD-deficient cells displayed resistance to TRAIL-mediated death, indicating that FADD played an essential role. Moreover, immunoprecipitation of the endogenous components of the DISC, in several different cell lines, have shown that FADD/caspase- 8 are indeed recruited by DR 4 and 5 and that cells lacking these are resistant to TRAIL-mediated

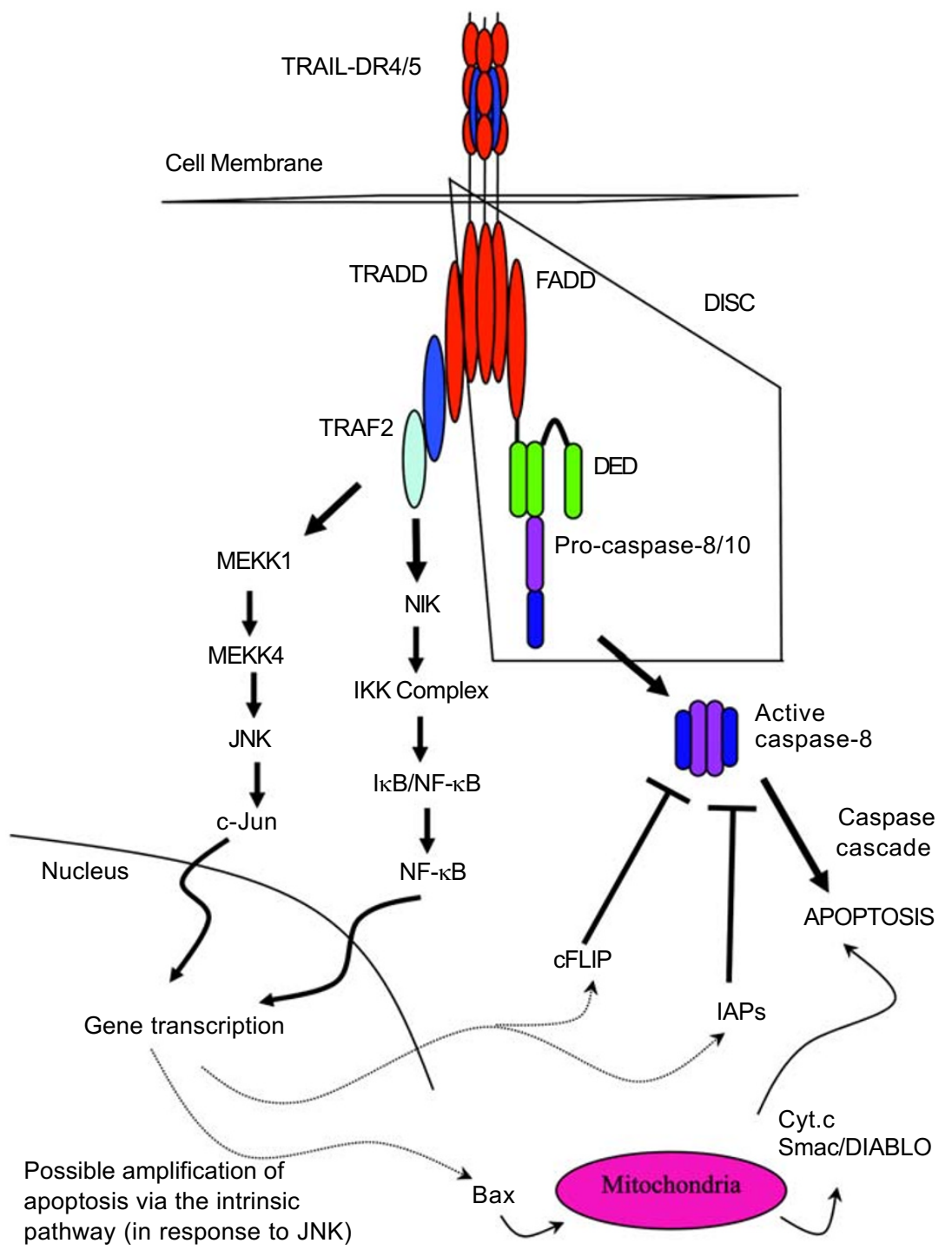

Fig. 8 TRAIL receptor signalling. Schematic showing the major signalling pathways initiated following TRAIL ligation of DR4 or DR5. The major pathway is the initiation of apoptosis. However, there is also some NF- $\mathrm{KB}$ and c-Jun activation. These transcription factors can have an anti-apoptotic effect via the up-regulation of pro-survival genes, or can amplify the apoptotic signal through transcription of genes that can act via the mitochondria (the intrinsic pathway). 
apoptosis $[99,114,115]$. To conclude this debate, a direct interaction between the death domain (DD) of DR5 and the DED of FADD has now been shown [116]. A similar discrepancy occurred regarding the proposed role of a GTP-dependent adaptor molecule called DAP3. It was reported to link DR4 and 5 to FADD via a high affinity interaction [117]. However, later studies disputed this, claiming it was an artefact of cellular disruption, and showed location of DAP-3 to be exclusively in the mitochondrial matrix, acting as a pro-apoptotic protein through a different mechanism [118-120].

Following initial adaptor recruitment, caspases are recruited and then the proteolytic caspase cascade, terminating in cleavage of crucial cellular proteins, begins. Caspase- 8 was originally shown to be the initiator caspase in TRAIL signalling, although caspase-10 was also found to be recruited to, and activated, at the DISC [121]. It appeared they were functionally redundant, but it has since been shown that caspase-10 cannot functionally substitute for caspase-8 [122].

While apoptosis is the major signalling outcome for the TRAIL death receptors, they can also activate survival signals via the transcription factor $\mathrm{NF}-\kappa \mathrm{B}$, which can up-regulate anti-apoptotic genes. The induction of NF- $\kappa \mathrm{B}$ is thought to be secondary to their ability to signal apoptosis, primarily occurring in a self-regulatory capacity $[100,111]$, and this is supported by data showing that $\mathrm{NF}-\kappa \mathrm{B}$ production emanating from the TRAIL receptors is much weaker than that from TNFR1. In addition, whilst activation of NF- $\kappa \mathrm{B}$ leads to a marked decrease in TRAIL apoptosis, activation of NF- $\kappa \mathrm{B}$ can only occur in TRAIL sensitive cells in the presence of the caspase inhibitor z-VAD-fmk [123]. Other experiments have shown that activation of NF- $\kappa \mathrm{B}$ alone is not sufficient for inhibition of apoptosis via DR4 and 5 [100].

The activation of a second transcription factor, c-Jun, can also occur, but whether this then mediates mainly pro- or anti-apoptotic signals is not clear. There are two distinct signaling pathways for transcription factor activation, which begin with the recruitment of common adaptors [100]. The first step is the recruitment of TRADD, the TNF receptor associated death domain which, like FADD, binds to the death domain through its homologous region [111]. This then recruits another adaptor, receptor interacting protein, RIP, which also binds via a death domain. Receptor interacting protein (RIP) is a serinethreonine kinase capable of stimulating auto-phosphorylation. Finally, TRAF-2 is recruited to RIP and this is the pivotal component for the two pathways, resulting in activation of either the c-Jun NH2-terminal kinase (JNK) pathway mediated via MEKK1/MKK4 or NF- $\kappa \mathrm{B}$, mediated via the NIK/IKK complex.

TRAIL has been shown to activate JNK via both caspase-dependent and independent pathways [124]. Induction of the JNK pathway was shown to have an amplifying effect on TRAIL-induced apoptosis through the intrinsic pathway [125]. There is some evidence to suggest that the JNK pathway is initiated by DR5 but not DR4, and that these receptors have distinct cross-linking requirements for activation [126]. This is the only evidence to suggest a difference in the signalling capacities of these two receptors. However, studies, using monoclonal antibodies against both DR4 and 5, and chemotherapeutic agents, show synergistic activation of the p38 and JNK signalling pathways which can be inhibited by blocking caspase-8 [127, 128]. Such activation seems to be celltype dependent, and whether this occurs in response to TRAIL in a normal physiological setting has not been shown. Activation of the extracellular signal regulated kinase (ERK) signalling has also been described for TRAIL but this is much less well-defined [129].

Since the signalling components of DR4 and DR5 are the same, i.e. recruitment of FADD and activation of caspase- 8 or -10 , it has been suggested that the formation of heteromeric complexes between DR4 and DR5 are possible, and that the outcome of their ligation would be functionally indistinguishable. However, two separate studies have shown that whilst DR4 is activated in response to both soluble and membrane-bound TRAIL, DR5 will only respond to cross-linked or membrane-bound TRAIL; DR5 became sensitive to a soluble form of TRAIL upon tethering to a membrane $[3,126]$. This result was not reflected in the work by Tecchio et al in which soluble TRAIL released from IFN $\gamma$-stimulated monocytes was able to kill both DR4 and 5 expressing cells [4]. Perhaps this difference limits the formation of mixed complexes, which have been shown [99]. TRAIL receptor signalling is subject to regulation from c-FLIP, a high ratio of which is thought to explain cellular resistance to TRAIL apoptosis in some instances $[25,123]$. Proteins from the IAP family (Inhibitors of apoptosis) which have a common BIRmotif (baculovirus IAP repeat) can also inhibit caspases and modulate apoptosis, and cell death that is amplified via the mitochondrial pathway will also be subject to regulation via the Bcl-2 superfamily (reviewed in [130]).

\section{Conclusions}

Many of the early experiments in apoptosis were conducted with over-expressed, transfected receptors rather than endogenous ones. It is now a well described phenomenon that over-expression of death receptors can induce cell death via non-specific aggregation of the death domains, the subsequent activation of caspases occurring through trans-proteolysis through weak protease activity possessed by the pro-forms in the 'induced-proximity' mechanism (reviewed in [131]). This is accepted as dis- 
tinct from ligand-receptor induced signalling and is not a good model for analysis of the necessary molecular components. It is possible that this phenomenon may explain some of the early misconceptions in defining the signaling pathways. Likewise, the use of monoclonal antibody cross-linking of the receptors is informative of a cell's susceptibility to death under potential therapeutic conditions, but one must be cautious in extracting too much with respect to true signalling mechanisms.

The story of the TRAIL and its receptors is one of complexity, conflicting results and apparent parody. In a system where there is undoubtedly interplay between several receptors, possible redundancy and differing expression and sensitivity between different tissues, this can only be expected. Research on the decoys has been slow to emerge, but it will be interesting to see new data regarding the signalling capacities of both DcR1 and 2, and other possible binding partners. The potential of TRAIL as an effective systemic anti-cancer drug will be limited until the deleterious effects can be regulated within the different tissues, and understanding how the TRAIL receptors regulate themselves will prove crucial to this cause.

\section{Acknowledgements}

Thanks to Juthathip Mongkolsapaya for useful comments and discussions, and to Adrian Lobito for help with some of the figures. We apologise to the scientists whose work has not been mentioned; in order to review such a heavily researched subject only a selection of the work reflecting the major themes on TRAIL and its receptors have been discussed here.

\section{References}

1 Pitti RM, Marsters SA, Ruppert S, et al. Induction of apoptosis by Apo-2 ligand, a new member of the tumor necrosis factor cytokine family. J Biol Chem 1996; 271:12687-90.

2 Wiley SR, Schooley K, Smolak PJ, et al. Identification and characterization of a new member of the TNF family that induces apoptosis. Immunity 1995; 3:673-82.

3 Wajant H, Moosmayer D, Wuest T, et al. Differential activation of TRAIL-R1 and -2 by soluble and membrane TRAIL allows selective surface antigen-directed activation of TRAIL-R2 by a soluble TRAIL derivative. Oncogene 2001; 20:4101-6.

4 Tecchio C, Huber V, Scapini P, et al. IFN $\alpha$-stimulated neutrophils and monocytes release a soluble form of TNF-related apoptosis-inducing ligand (TRAIL/Apo-2 ligand) displaying apoptotic activity on leukemic cells. Blood 2004;103:3837-44

5 Pan G, O'Rourke K, Chinnaiyan AM, et al. The receptor for the cytotoxic ligand TRAIL. Science 1997; 276:111-3.

6 Walczak H, Degli-Esposti MA, Johnson RS, et al. TRAIL-R2: a novel apoptosis-mediating receptor for TRAIL. Embo J 1997; 16:5386-97.

7 MacFarlane M, Ahmad M, Srinivasula SM, et al. Identification and molecular cloning of two novel receptors for the cytotoxic ligand TRAIL. J Biol Chem 1997; 272:25417-20.
8 Screaton GR, Mongkolsapaya J, Xu XN, et al. TRICK2, a new alternatively spliced receptor that transduces the cytotoxic signal from TRAIL. Curr Biol 1997; 7:693-6.

9 Degli-Esposti MA, Dougall WC, Smolak PJ, et al. The novel receptor TRAIL-R4 induces NF-kappaB and protects against TRAIL-mediated apoptosis, yet retains an incomplete death domain. Immunity 1997; 7:813-20.

10 Degli-Esposti MA, Smolak PJ, Walczak H, et al. Cloning and characterization of TRAIL-R3, a novel member of the emerging TRAIL receptor family. J Exp Med 1997; 186:1165-70.

11 Pan G, Ni J, Wei YF, et al. An antagonist decoy receptor and a death domain-containing receptor for TRAIL. Science 1997; 277: 815-8.

12 Pan G, Ni J, Yu G, et al. TRUNDD, a new member of the TRAIL receptor family that antagonizes TRAIL signalling. FEBS Lett 1998; 424:41-5.

13 Mongkolsapaya J, Cowper AE, Xu XN, et al. Lymphocyte inhibitor of TRAIL (TNF-related apoptosis-inducing ligand): a new receptor protecting lymphocytes from the death ligand TRAIL. J Immunol 1998; 160:3-6.

14 Emery JG, McDonnell P, Burke MB, et al. Osteoprotegerin is a receptor for the cytotoxic ligand TRAIL. J Biol Chem 1998; 273:14363-7.

15 Griffith, T.S., Chin, W.A., Jackson, G.C., et al. Intracellular regulation of TRAIL-induced apoptosis in human melanoma cells. J Immunol(1998) 161, 2833-40.

16 Meng RD, McDonald ER 3rd, Sheikh MS, et al. The TRAIL decoy receptor TRUNDD (DcR2, TRAIL-R4) is induced by adenovirus-p53 overexpression and can delay TRAIL-, p53-, and KILLER/DR5-dependent colon cancer apoptosis. Mol Ther 2000; 1:130-44.

17 Walczak H, Miller RE, Ariail K, et al. Tumoricidal activity of tumor necrosis factor-related apoptosis- inducing ligand in vivo. Nat Med 1999; 5:157-63.

18 Ashkenazi A, Pai RC, Fong S, et al. Safety and antitumor activity of recombinant soluble Apo2 ligand. J Clin Invest 1999;104: 155-62.

19 Mitsiades CS, Treon SP, Mitsiades N, et al. TRAIL/Apo2L ligand selectively induces apoptosis and overcomes drug resistance in multiple myeloma: therapeutic applications. Blood 2001; 98:795-804.

20 Wen J, Ramadevi N, Nguyen D, et al. Antileukemic drugs increase death receptor 5 levels and enhance Apo-2L-induced apoptosis of human acute leukemia cells. Blood 2000; 96:3900-6.

21 Kim K, Fisher MJ, Xu SQ, el-Deiry WS. Molecular determinants of response to TRAIL in killing of normal and cancer cells. Clin CancerRes 2000; 6:335-46.

22 Nagane M, Pan G, Weddle JJ, et al. Increased death receptor 5 expression by chemotherapeutic agents in human gliomas causes synergistic cytotoxicity with tumor necrosis factor-related apoptosis-inducing ligand in vitro and in vivo. Cancer Res 2000; 60:847-53.

23 Keane MM, Ettenberg SA, Nau MM, et al. Chemotherapy augments TRAIL-induced apoptosis in breast cell lines. Cancer Res1999; 59:734-41.

24 Mori S, Murakami-Mori K, Nakamura S, et al. Sensitization of AIDSKaposi's sarcoma cells to Apo-2 ligand-induced apoptosis by actinomycin D. J Immunol 1999; 162:5616-23.

25 Ganten TM, Haas TL, Sykora J, et al. Enhanced caspase-8 recruitment to and activation at the DISC is critical for sensitisation of human hepatocellular carcinoma cells to TRAIL- 
induced apoptosis by chemotherapeutic drugs. Cell Death Differ 2004; 11:S86-96

26 Belka C, Schmid B, Marini P, et al. Sensitization of resistant lymphoma cells to irradiation-induced apoptosis by the death ligand TRAIL. Oncogene 2001; 20:2190-6.

27 Jo M, Kim TH, Seol DW, et al. Apoptosis induced in normal human hepatocytes by tumor necrosis factor- related apoptosisinducing ligand. Nat Med 2000; 6:564-7.

taf/DynaPage.taf?file=/nm/journal/v566/n565/full/nm0500_0564. html

taf/DynaPage.taf?file $=/ \mathrm{nm} /$ journal $/ \mathrm{v} 0506 / \mathrm{n} 0505 / \mathrm{abs} /$ nm0500_0564.html.

28 Zheng SJ, Wang P, Tsabary G, Chen YH Critical roles of TRAIL in hepatic cell death and hepatic inflammation. J Clin Invest 2004; 113:58-64.

29 Ichikawa K, Liu W, Zhao L, et al. Tumoricidal activity of a novel antihuman DR5 monoclonal antibody without hepatocyte cytotoxicity. Nat Med 2001; 7:954-60.

30 Taimr P, Higuchi H, Kocova E, et al. Activated stellate cells express the TRAIL receptor-2/death receptor-5 and undergo TRAIL-mediated apoptosis. Hepatology 2003; 37:87-95.

31 Lamhamedi-Cherradi SE, Zheng SJ, Maguschak KA, et al. Defective thymocyte apoptosis and accelerated autoimmune diseases in TRAIL $^{-/}$mice. Nat Immunol 2003; 4:255-60.

32 Simon AK, Williams O, Mongkolsapaya J, et al. Tumor necrosis factorrelated apoptosis-inducing ligand in T cell development: sensitivity of human thymocytes. Proc Natl Acad Sci U S A 2001; 98:5158-63.

33 Nesterov A, Ivashchenko Y, Kraft AS. Tumor necrosis factorrelated apoptosis-inducing ligand (TRAIL) triggers apoptosis in normal prostate epithelial cells. Oncogene 2002; 21:1135-40.

34 Martin-Villalba A, Herr I, Jeremias I, et al. CD95 ligand (Fas-L/ APO-1L) and tumor necrosis factor-related apoptosis-inducing ligand mediate ischemiainduced apoptosis in neurons. J Neurosci 1999; 19:3809-17.

35 Galle PR, Hofmann WJ, Walczak H, et al. Involvement of the CD95 (APO-1/Fas) receptor and ligand in liver damage. J Exp Med 1995; 182:1223-30.

36 Anderson GM, Nakada MT, DeWitte M. Tumor necrosis factor-alpha in the pathogenesis and treatment of cancer. Curr Opin Pharmacol 2004; 4:314-20.

37 Wuchter C, Krappmann D, Cai Z, et al. In vitro susceptibility to TRAILinduced apoptosis of acute leukemia cells in the context of TRAIL receptor gene expression and constitutive NF- $\kappa \mathrm{B}$ activity. Leukemia 2001; 15:921-8.

38 Lincz LF, Yeh TX, Spencer A. TRAIL-induced eradication of primary tumour cells from multiple myeloma patient bone marrows is not related to TRAIL receptor expression or prior chemotherapy. Leukemia 2001; 15:1650-7.

39 Mirandola P, Ponti C, Gobbi G, et al. Activated human NK and $\mathrm{CD}^{+} \mathrm{T}$ cells express both TNF-related apoptosis inducing ligand (TRAIL) and TRAIL receptors, but are resistant to TRAILmediated cytotoxicity. Blood 2004; 104:2418-24.

40 Zhang XD, Franco A, Myers K, et al. Relation of TNF-related apoptosisinducing ligand (TRAIL) receptor and FLICE-inhibitory protein expression to TRAIL-induced apoptosis of melanoma. Cancer Res 1999; 59:2747-53.

41 Wu GS, Kim K, el-Deiry WS. KILLER/DR5, a novel DNAdamage inducible death receptor gene, links the p53-tumor suppressor to caspase activation and apoptotic death. Adv Exp Med Biol 2000; 465:143-51.
42 Wu GS, Burns TF, McDonald ER 3rd, et al. KILLER/DR5 is a DNA damage-inducible p53-regulated death receptor gene. Nat Genet 1997; 17:141-3.

43. Koyama S, Koike N, Adachi S. Expression of TNF-related apoptosisinducing ligand (TRAIL) and its receptors in gastric carcinoma and tumorinfiltrating lymphocytes: a possible mechanism of immune evasion of the tumor. J Cancer Res Clin Oncol 2002; 128:73-9.

44 Castro JE, Listman JA, Jacobson BA, et al. Fas modulation of apoptosis during negative selection of thymocytes. Immunity 1996; 5:617-27.

45. Adachi, M., Suematsu, S., Suda, T., et al. Enhanced and accelerated lymphoproliferation in Fas-null mice. Proc Natl Acad Sci U S A(1996) 93, 2131-2136.

46 Green DR, Droin N, Pinkoski M. Activation-induced cell death in T cells. Immunol Rev 2003; 193:70-81.

47 Sedger LM, Glaccum MB, Schuh JC, et al. Characterization of the in vivo function of TNF-alpha-related apoptosis-inducing ligand, TRAIL/Apo2L, using TRAIL/Apo2L gene-deficient mice. Eur J Immunol 2002; 32:2246- 54.

48 Kabra NH, Kang C, Hsing LC, et al. T cell-specific FADDdeficient mice: FADD is required for early $\mathrm{T}$ cell development. Proc Natl Acad Sci U S A 2001; 98:6307-12.

49 Walsh CM, Wen BG, Chinnaiyan AM, et al. A role for FADD in T cell activation and development. Immunity 1998; 8:439-49.

50 Bouillet P, Purton JF, Godfrey DI, et al. BH3-only Bcl-2 family member Bim is required for apoptosis of autoreactive thymocytes. Nature 2002; 415:922-6.

51 Green DR. The suicide in the thymus, a twisted trail. Nat Immunol 2003; 4:207-8

52 Cretney E, Uldrich AP, Berzins SP, et al. Normal thymocyte negative selection in TRAIL-deficient mice. J Exp Med 2003 198:491-6.

53 Smyth MJ, Cretney E, Takeda K, et al. Tumor necrosis factorrelated apoptosis-inducing ligand (TRAIL) contributes to interferon gamma24 dependent natural killer cell protection from tumor metastasis. J Exp Med 2001; 193:661-70.

54 Takeda K, Smyth MJ, Cretney E, et al. Critical role for tumor necrosis factor-related apoptosis-inducing ligand in immune surveillance against tumor development. J Exp Med 2002; 195: 161-9.

55 Fanger NA, Maliszewski CR, Schooley K, Griffith TS. Human dendritic cells mediate cellular apoptosis via tumor necrosis factor-related apoptosis-inducing ligand (TRAIL). J Exp Med 1999; 190:1155-64.

56 Kayagaki N, Yamaguchi N, Nakayama M, et al. Type I interferons (IFNs) regulate tumor necrosis factor-related apoptosis-inducing ligand (TRAIL) expression on human T cells: A novel mechanism for the antitumor effects of type I IFNs. J Exp Med 1999; 189: $1451-60$.

57 Thomas WD, Hersey P. TNF-related apoptosis-inducing ligand (TRAIL) induces apoptosis in Fas ligand-resistant melanoma cells and mediates CD4 T cell killing of target cells. J Immunol 1998; 161:2195-200.

58. Sedger LM, Shows DM, Blanton RA, et al. IFN- $\gamma$ mediates a novel antiviral activity through dynamic modulation of TRAIL and TRAIL receptor expression. J Immunol 1999;163:920-6.

59 Jeremias I, Herr I, Boehler T, Debatin KM. TRAIL/Apo-2ligandinduced apoptosis in human T cells. Eur J Immunol 1998; 28:143-52.

60 Katsikis PD, Garcia-Ojeda ME, Torres-Roca JF, et al. Interleukin- 
$1 \beta$ converting enzyme-like protease involvement in Fas-induced and activationinduced peripheral blood T cell apoptosis in HIV infection. TNF-related apoptosis-inducing ligand can mediate activation-induced T cell death in HIV infection. J Exp Med 1997;186:1365-72.

61 Miura Y, Misawa N, Maeda N, et al. Critical contribution of tumor necrosis factor-related apoptosis-inducing ligand (TRAIL) to apoptosis of human CD4+ T cells in HIV-1-infected hu-PBLNOD-SCID mice. J Exp Med 2001; 193:651-60.

62 Strater J, Walczak H, Pukrop T, et al. TRAIL and its receptors in the colonic epithelium: a putative role in the defense of viral infections. Gastroenterology 2002; 122:659-666.

63 Phillips TA, Ni J, Pan G, et al. TRAIL (Apo-2L) and TRAIL receptors in human placentas: implications for immune privilege. J Immunol 1999; 162:6053-9.

64 Lee HO, Herndon JM, Barreiro R, et al. TRAIL: a mechanism of tumor surveillance in an immune privileged site. J Immunol 2002; 169:4739-44

65 Ursini-Siegel J, Zhang W, Altmeyer A, et al. TRAIL/Apo-2 ligand induces primary plasma cell apoptosis. J Immunol 2002; 169: 5505-13.

66 Zamai L, Secchiero P, Pierpaoli S, et al. TNF-related apoptosisinducing ligand (TRAIL) as a negative regulator of normal human erythropoiesis. Blood 2000; 95: 3716-24.

67 Secchiero P, Gonelli A, Carnevale E, et al. Evidence for a proangiogenic activity of TNF-related apoptosis-inducing ligand. Neoplasia 2004; 6:364- 73.

68 Li JH, Kirkiles-Smith NC, McNiff JM, Pober JS. TRAIL induces apoptosis and inflammatory gene expression in human endothelial cells. J Immunol 2003; 171:1526-33.

69 Clarke P, Meintzer SM, Gibson S, et al. Reovirus-induced apoptosis is mediated by TRAIL. J Virol 2000; 74:8135-9.

$70 \mathrm{Wu}$ GS, Burns TF, Zhan Y, et al. Molecular cloning and functional analysis of the mouse homologue of the KILLER/DR5 tumor necrosis factorrelated apoptosis-inducing ligand (TRAIL) death receptor. Cancer Res 1999; 59:2770-5.

71 Schneider P, Olson D, Tardivel A, et al. Identification of a new murine tumor necrosis factor receptor locus that contains two novel murine receptors for tumor necrosis factor-related apoptosis-inducing ligand (TRAIL). J Biol Chem 2003; 278: 5444-54.

72 Mongkolsapaya J, Grimes JM, Chen N, et al. Structure of the TRAILDR5 complex reveals mechanisms conferring specificity in apoptotic initiation. Nat Struct Biol 1999;6:1048-53.

73 Cha SS, Sung BJ, Kim YA, et al. Crystal structure of TRAILDR5 complex identifies a critical role of the unique frame insertion in conferring recognition specificity. J Biol Chem 2000; 275:31171-7.

74 Hymowitz SG, Christinger HW, Fuh G, et al. Triggering cell death: the crystal structure of Apo2L/TRAIL in a complex with death receptor 5. Mol Cell 1999; 4:563-71.

75 Siegel RM, Frederiksen JK, Zacharias DA, et al. Fas preassociation required for apoptosis signaling and dominant inhibition by pathogenic mutations. Science 2000; 288:2354-7.

76 Chan FK, Chun HJ, Zheng L, et al. A domain in TNF receptors that mediates ligand-independent receptor assembly and signaling. Science 2000; 288:2351-4.

77 Locksley RM, Killeen N, Lenardo MJ. The TNF and TNF receptor superfamilies: integrating mammalian biology. Cell 2001; 104: 487-501.

78 Pai SI, Wu GS, Ozoren N, et al. Rare loss-of-function mutation of a death receptor gene in head and neck cancer. Cancer Res 1998; 58:3513-8.

79 Park WS, Lee JH, Shin MS, et al. Inactivating mutations of KILLER/DR5 gene in gastric cancers. Gastroenterology 2001; 121:1219- 25.

80 Bedi A, Mookerjee B. Biological significance and molecular mechanisms of p53-induced apoptosis. Apoptosis 1998; 3:237-44.

81 Burns TF, Bernhard EJ, El-Deiry WS. Tissue specific expression of p53 target genes suggests a key role for KILLER/DR5 in p53-dependent apoptosis in vivo. Oncogene 2001; 20:4601-12.

82 Takimoto R, El-Deiry WS. Wild-type p53 transactivates the KILLER/DR5 gene through an intronic sequence-specific DNAbinding site. Oncogene 2000; 19:1735-43.

83 Ichikawa K, Liu W, Fleck M, et al. TRAIL-R2 (DR5) mediates apoptosis of synovial fibroblasts in rheumatoid arthritis. J Immunol 2003; 171:1061-9.

84 Buchsbaum DJ, Zhou T, Grizzle WE, et al. Antitumor efficacy of TRA-8 anti-DR5 monoclonal antibody alone or in combination with chemotherapy and/or radiation therapy in a human breast cancer model. Clin Cancer Res 2003; 9:3731-41.

85 Lee SH, Shin MS, Kim HS, et al. Somatic mutations of TRAILreceptor 1 and TRAIL-receptor 2 genes in non-Hodgkin's lymphoma. Oncogene 2001; 20:399-403.

86 Ozoren N, Fisher MJ, Kim K, et al. Homozygous deletion of the death receptor DR4 gene in a nasopharyngeal cancer cell line is associated with TRAIL resistance. Int J Oncol 2000; 16:917-25.

87 Shin MS, Kim HS, Lee SH, et al. Mutations of tumor necrosis factorrelated apoptosis-inducing ligand receptor 1 (TRAIL-R1) and receptor 2 (TRAIL-R2) genes in metastatic breast cancers. Cancer Res 2001; 61:4942- 6.

88 Hazra A, Chamberlain RM, Grossman HB, et al. Death receptor 4 and bladder cancer risk. Cancer Res 2003; 63:1157-9.

89 Strater J, Hinz U, Walczak H, et al. Expression of TRAIL and TRAIL receptors in colon carcinoma: TRAIL-R1 is an independent prognostic parameter. Clin Cancer Res 2002; 8:3734-40.

90 Mitsiades N, Poulaki V, Mitsiades C, Tsokos M. Ewing's sarcoma family tumors are sensitive to tumor necrosis factorrelated apoptosis-inducing ligand and express death receptor 4 and death receptor 5. Cancer Res 2001; 61:2704-12.

$91 \mathrm{Wu}$ XX, Kakehi Y, Mizutani Y, et al. Enhancement of TRAIL/ Apo2Lmediated apoptosis by adriamycin through inducing DR4 and DR5 in renal cell carcinoma cells. Int J Cancer 2003; 104: 409-17.

92 Nimmanapalli R, Perkins CL, Orlando M, et al. Pretreatment with paclitaxel enhances apo-2 ligand/tumor necrosis factorrelated apoptosisinducing ligand-induced apoptosis of prostate cancer cells by inducing death receptors 4 and 5 protein levels. Cancer Res 2001; 61:759-63.

93 Tollefson, A.E., Toth, K., Doronin, K., et al. Inhibition of TRAILinduced apoptosis and forced internalization of TRAIL receptor 1 by adenovirus proteins. J Virol 2001; 75:8875-87.

94 Janssen HL, Higuchi H, Abdulkarim A, Gores GJ. Hepatitis B virus enhances tumor necrosis factor-related apoptosis-inducing ligand (TRAIL) cytotoxicity by increasing TRAIL-R1/death receptor 4 expression. J Hepatol 2003; 39:414-20.

95 Horejsi V, Drbal K, Cebecauer M, et al. GPI-microdomains: a role in signalling via immunoreceptors. Immunol Today 1999; 20:356-61.

96 Truneh A, Sharma S, Silverman C, et al. Temperature-sensitive differential affinity of TRAIL for its receptors. DR5 is the highest affinity receptor. J Biol Chem 2000; 275:23319-25. 
97 Sheikh MS, Huang Y, Fernandez-Salas EA, et al. The antiapoptotic decoy receptor TRID/TRAIL-R3 is a p53-regulated DNA damage-inducible gene that is overexpressed in primary tumors of the gastrointestinal tract. Oncogene 1999; 18:4153-9.

98 Bernard D, Quatannens B, Vandenbunder B, Abbadie C. Rel/NF$\kappa \mathrm{B}$ transcription factors protect against tumor necrosis factor (TNF)-related apoptosis-inducing ligand (TRAIL)-induced apoptosis by up-regulating the TRAIL decoy receptor DcR1. J Biol Chem 2001; 276:27322-8.

99 Kischkel FC, Lawrence DA, Chuntharapai A, et al. Apo2L/ TRAILdependent recruitment of endogenous FADD and caspase8 to death receptors 4 and 5 . Immunity $2000 ; \mathbf{1 2}: 611-20$.

$100 \mathrm{Hu} \mathrm{WH}$, Johnson H, Shu HB. Tumor necrosis factor-related apoptosis-inducing ligand receptors signal NF- $\kappa B$ and JNK activation and apoptosis through distinct pathways. J Biol Chem 1999; 274:30603-10.

101 Simonet WS, Lacey DL, Dunstan CR, et al. Osteoprotegerin: a novel secreted protein involved in the regulation of bone density. Cell 1997; 89:309-19.

102Bengtsson AK, Ryan EJ. Immune function of the decoy receptor osteoprotegerin. Crit Rev Immunol 2002; 22:201-215.

103 Yun TJ, Tallquist MD, Aicher A, et al. Osteoprotegerin, a crucial regulator of bone metabolism, also regulates $\mathrm{B}$ cell development and function. J Immunol 2001; 166:1482-91.

104 Pritzker LB, Scatena M, Giachelli CM. The role of osteoprotegerin and tumor necrosis factor-related apoptosis-inducing ligand in human microvascular endothelial cell survival. Mol Biol Cell 2004; 15:2834-41.

105Zauli G, Rimondi E, Nicolin V, et al. TNF-related apoptosis inducingligand (TRAIL) blocks osteoclastic differentiation induced by RANKL+MCSF. Blood 2004; .

106 Kischkel FC, Hellbardt S, Behrmann I, et al. Cytotoxicity-dependent APO-1 (Fas/CD95)-associated proteins form a deathinducing signaling complex (DISC) with the receptor. Embo J 1995; 14:5579-88.

107 Medema JP, Scaffidi C, Kischkel FC, et al. FLICE is activated by association with the CD95 death-inducing signaling complex (DISC). Embo J 1997; 16:2794-804.

108Chinnaiyan AM, O'Rourke K, Tewari M, Dixit VM. FADD, a novel death domain-containing protein, interacts with the death domain of Fas and initiates apoptosis. Cell 1995; 81:505-12.

109Boldin MP, Mett IL, Varfolomeev EE, et al. Self-association of the "death domains" of the p55 tumor necrosis factor (TNF) receptor and Fas/APO1 prompts signaling for TNF and Fas/ APO1 effects. J Biol Chem 1995; 270:387-91.

110 Sheridan JP, Marsters SA, Pitti RM, et al. Control of TRAILinduced apoptosis by a family of signaling and decoy receptors. Science 1997; 277:818-21.

111 Chaudhary PM, Eby M, Jasmin A, et al. Death receptor 5, a new member of the TNFR family, and DR4 induce FADD- dependent apoptosis and activate the NF-kappaB pathway. Immunity 1997; 7:821-30.

112 Schneider P, Thome M, Burns K, et al. TRAIL receptors 1 (DR4) and 2 (DR5) signal FADD-dependent apoptosis and activate NF-kappaB. Immunity 1997; 7:831-6.

113 Kuang AA, Diehl GE, Zhang J, Winoto A. FADD is required for DR4- and DR5-mediated apoptosis: lack of trail-induced apoptosis in FADDdeficient mouse embryonic fibroblasts. J Biol Chem 2000; 275:25065-8.

114 Sprick MR, Weigand MA, Rieser E, et al. FADD/MORT1 and caspase- 8 are recruited to TRAIL receptors 1 and 2 and are essential for apoptosis mediated by TRAIL receptor 2 . Immunity 2000; 12:599-609.

115Bodmer JL, Holler N, Reynard S, et al. TRAIL receptor-2 signals apoptosis through FADD and caspase-8. Nat Cell Biol 2000; 2: 241-3.

116Thomas LR, Henson A, Reed JC, et al. Direct binding of Fasassociated death domain (FADD) to the tumor necrosis factorrelated apoptosisinducing ligand receptor DR5 is regulated by the death effector domain of FADD. J Biol Chem 2004; 279: 32780-5.

117Miyazaki T, Reed JC. A GTP-binding adapter protein couples TRAIL receptors to apoptosis-inducing proteins. Nat Immunol 2001; 2:493-500.

118 Berger T, Kretzler M. Interaction of DAP3 and FADD only after cellular disruption. Nat Immunol 2002; 3:3-5.

119Kissil JL, Deiss LP, Bayewitch M, et al. Isolation of DAP3, a novel mediator of interferon-gamma-induced cell death. J Biol Chem 1995; 270:27932-6.

120Kissil JL, Cohen O, Raveh T, Kimchi A. Structure-function analysis of an evolutionary conserved protein, DAP3, which mediates TNF- $\alpha$ - and Fas-induced cell death. Embo J 1999; 18: 353-362.

121 Kischkel FC, Lawrence DA, Tinel A, et al. Death receptor recruitment of endogenous caspase-10 and apoptosis initiation in the absence of caspase-8. J Biol Chem 2001; 276:46639-46.

122 Sprick MR, Rieser E, Stahl H, et al. Caspase-10 is recruited to and activated at the native TRAIL and CD95 death-inducing signalling complexes in a FADD-dependent manner but can not functionally substitute caspase-8. Embo J 2002; 21, 4520-4530.

123 Harper N, Farrow SN, Kaptein A, et al. Modulation of tumor necrosis factor apoptosis-inducing ligand-induced NF- $\kappa \mathrm{B}$ activation by inhibition of apical caspases. J Biol Chem 2001; 276: 34743-52.

124Muhlenbeck F, Haas E, Schwenzer R, et al. TRAIL/Apo2L activates c-Jun NH2-terminal kinase JNK) via caspase- dependent and caspase-independent pathways. J Biol Chem 1998; 273: 33091-8.

125 Herr I, Wilhelm D, Meyer E, et al. JNK/SAPK activity contributes to TRAIL-induced apoptosis. Cell Death Differ 1999; 6:130-135.

126 Muhlenbeck F, Schneider P, Bodmer JL, et al. The tumor necrosis factorrelated apoptosis-inducing ligand receptors TRAIL-R1 and TRAIL-R2 have distinct cross-linking requirements for initiation of apoptosis and are nonredundant in JNK activation. $\mathrm{J}$ Biol Chem 2000; 275:32208-13.

127 Ohtsuka T, Buchsbaum D, Oliver P, et al. Synergistic induction of tumor cell apoptosis by death receptor antibody and chemotherapy agent through $\mathrm{JNK} / \mathrm{p} 38$ and mitochondrial death pathway. Oncogene 2003; 22:2034-2044.

128Ohtsuka T, Zhou T. Bisindolylmaleimide VIII enhances DR5mediated apoptosis through the MKK4/JNK/p38 kinase and the mitochondrial pathways. J Biol Chem 2002; 277:29294303.

129Secchiero P, Melloni E, Heikinheimo M, et al. TRAIL regulates normal erythroid maturation through an ERK-dependent pathway. Blood 2004; 103:517-522.

130 Sprick MR, Walczak H. The interplay between the Bcl-2 family and death receptor-mediated apoptosis. Biochim Biophys Acta 2004; 1644:125-132.

131 Salvesen GS, Dixit VM. Caspase activation: the induced-proximity model. Proc Natl Acad Sci U S A 1999; 96:10964-7. 